\title{
TUMOUR OF THE SUPRARENAL CORTEX IN AN INFANT OF 18 WEEKS
}

\author{
BY
}

\author{
REGINALD LIGHTWOOD, M.D., M.R.C.P., D.P.H. \\ (From the Hospital for Sick Children, Great Ormond Street, London.)
}

The functional importance of the suprarenal medulla was recognized for some years before that of the cortex was fully appreciated. While animals can live perfectly well without the medullary portion, total adrenalectomy causes death. From this and other data it is known that the cortex produces one or more hormones indispensable to life, and it would appear that the cortex is by far the more important element. The part played by these cortical hormones in the growth and maintenance of the genital system and of the secondary sexual characters has been a fertile field of study in which distinction has been won by physicians, pathologists, anatomists and physiologists alike.

As early as 1806, F. Meckel $^{1}$, from studies in comparative anatomy, developed the idea of a relationship between the suprarenals and the sexual organs, his belief being that animals with prepotent sexual powers had large suprarenals. It does not appear that he recognized the separate importance of the suprarenal cortex. In $1816 \mathrm{Otto}^{2}$ reported hypertrophy of the genital organs associated with hypertrophy or the adrenal. In 1905, there appeared a classical paper by W. Bulloch and J. H. Sequeira ${ }^{3}$, who described a case of a neoplasm of the suprarenal cortex in a female of eleven years, manifesting hirsuties with precocious growth and menstruation. Their suspicion that the simultaneous occurrence of the suprarenal tumour with precocity was no matter of chance was confirmed by a study of the literature. Going back to 1756 they were able to review twelve cases (all in children), and to originate the idea that hyper-function of the suprarenal cortex was the cause of the precocity in such cases. Though Bulloch and Sequeira pointed out that there are certain tumours of the suprarenal in young children not associated with evidence of precocious development, they did not recognize that these involved essentially the medullary portion. The work of R. Hutchison ${ }^{4}$, R. S. Frew ${ }^{5}$ and others has placed these cases in an entirely separate group, now known by such names as medullary hypernephroma, sympathetic neuroblastoma and neurocytoma sympatheticum. Among the effects of tumours of the cortex Bulloch and Sequeira gave excessive growth, hirsuties, precocious puberty, adiposity and muscular over-development. The youngest of their cases was 14 months old, and the oldest 14 years old. The average age of their series was 5 years, and only two were observed after the age of 7 . This paper, which moulded physiological opinion regarding cortical function, has been followed by several notable contributions. In 1912, E. Glynn ${ }^{6}$ was able to add five more cases to the twelve already collected by Bulloch and 
Sequeira. He employed the term adrenal hypernephroma in his description, and tabulated the features of the seventeen cases to show that such hypernephromata are commoner in females and tend in them to increase the male primary and secondary sex characters at the expense of female characters. Further, he gave six examples of adrenal hypernephroma in young adult females associated with changes in sex characters, and he broke new ground by giving thirteen examples of the association of pseudohermaphroditism with bilateral hyperplasia of the adrenal glands, or of adrenal rests. His conclusions are of much interest:-

These cases .... may be roughly divided into two groups:-

Group 1. The adrenal enlargement is unilateral, microscopically neoplastic; it often produces metastases and directly, or indirectly, causes death; but growth takes place more slowly than most malignant tumours. The growth and its associated physiological and anatomical defects are most probably acquired.

Group 2. The adrenal enlargement is bilateral, microscopically hyperplastic. Metastases are absent, though rests may occur, and death is due to other causes. The adrenal lesions and their associated physiological and anatomical defects are most probably congenital.

The line of demarcation between those two groups, however, is not complete, for some of the cases are intermediate.

G. Holmes ${ }^{7}$ (1925) in a paper recording a case of virilism associated with suprarenal tumour in a female was able to show that complete recovery from the structural, functional and psychological changes occurring in virilism, could follow surgical removal of a tumour of the suprarenal cortex. He remarks that ' the disappearance of the virilism after operation is evidence as strong as we can hope to obtain from clinical sources of the causal relation in which the tumour stood to it.' Several other examples of successful surgical removal with disappearance of virilism have been recorded.

R. Hutchison ${ }^{8}$ has reported the interesting association of hemihypertrophy (hemi-macrosomia) with hypertrophy of the suprarenal on the same side, but it would appear that the suprarenal enlargement may have been a part of the process rather than its cause.

Though generally speaking it is correct to say that tumours and hyperplasias of the suprarenal cortex produce virilism, the exact nature of the clinical types produced depends on several factors, namely, on sex and age, and on the duration, rapidity and extent of the growth. The influence of sex and age has been worked out by Glynn and illustrated by tabulations of the features of the collected cases.

In children, the cases have been divided by L. Guthrie and W. Emery' into two types*:-(1) The ' infant Hercules' or muscular type. This occurs only in males. True sexual precocity may appear. (2) The obese type with hirsuties. This occurs in both sexes. Of these, the infant Hercules type is the better known, perhaps on account of its happy title; nevertheless, it is less common than is the obese type for the infant Hercules appears only in some of the male cases, whereas tumours of the suprarenal are commoner in females.

* This division was originally suggested by Dr. F. Parkes Weber. 
A good example of the infant Hercules clinical type is a case described by C. E. Adams ${ }^{10}$ as follows :-

Considering his age he presented remarkable appearances of precocious development. As a child nothing unusual had been observed, but puberty set in at the age of 10 years, from which time, although he increased little in height, he developed great muscular strength, excelled in athletic sports, and defeated all competitors. For two years his complexion had been observed to be plethoric and dusky, and during this period the growth of hair on his face had to be shaved almost daily. His general appearance was that of a sturdy little man. This boy died of a malignant growth of the left suprarenal cortex.

The obese type of suprarenal virilism manifests itself in adiposity and hypertrichosis, with or without precocious puberty. Guthrie and Emery's description of this type in children may be quoted:-

In precocious obesity the features are bloated, the cheeks swell with fatness, the complexion is dusky and congested. The fat is usually distributed evenly about the body, but the extremities may remain thin. Pads of fat are situated about the neck, breasts, and flanks; a lipomatous mass is sometimes seen between the shoulders. Guthrie's case occurred in a boy; an illustration of this child at $4 \frac{3}{4}$ years can be seen in 'Diseases of Children' (second edition), edited by $\mathbf{H}$. Thursfield and D. Paterson.

The youngest recorded instance of a cortical tumour is that of A. Collett ${ }^{11}$.

This was a female child in whom a growth of pubic hair was noticed between 6 and 8 months. This gradually became thicker, and spread to the limbs and trunk. She became fat and heavy, growing excessively. The voice became deep and rough. At 18 months she was above average length and weight, her head was large and her cheeks bulged. There was hair on the labia, mons Veneris, thighs, shoulders, and back. There was over-development of the clitoris, which became a penis-like organ with glands, corona, and prepuce, and on its under surface a urethral groove was to be seen. A left suprarenal tumour was removed when she was 2 years and 2 months old. Within two months of operation there was already striking improvement, the cheeks became smaller, she became more child-like in appearance, but even two years after operation she was not a normal child.

In Collett's case we have an excellent example of Guthrie's obese type in a female infant with hirsuties, and virilism amounting to pseudohermaphroditism.

A. D. Fordyce and W. H. Evans ${ }^{20}$ have recorded two cases of cortical hypernephroma, the first a male of $2 \frac{1}{4}$ who died after an operation for the removal of the tumour, the second a female of 2 years who in many respects resembled the infant described by Collett; recovery followed extirpation of the growth.

\section{Case report.}

Even younger than Collett's is the following case of a male infant in whom symptoms arose at eleven weeks, which brought him under observation at the age of eighteen weeks. This case was briefly presented before the British Pædiatric Association in 1931 by R. Hutchison and the writer ${ }^{12}$. The full details are now recorded for the first time.

A male infant, a fourth pregnancy, and one of twins, made good progress until the age of 11 weeks. Then the mother became aware that there was enlargement of his cheeks and chin. Subsequently she found diffuse swelling at the back of his neck and between the shoulder blades. The legs began to waste, advance in weight 
slowed down, and finally he began to lose. He ceased to take any interest in his surroundings, and thrush appeared. At the age of 18 weeks he was admitted to the Hospital for Sick Children under the care of Dr. Robert Hutchison.

The parents were healthy, and all their six children were alive. No serious illnesses had occurred among them, except tuberculous adenitis in the eldest. The other twin was thriving.

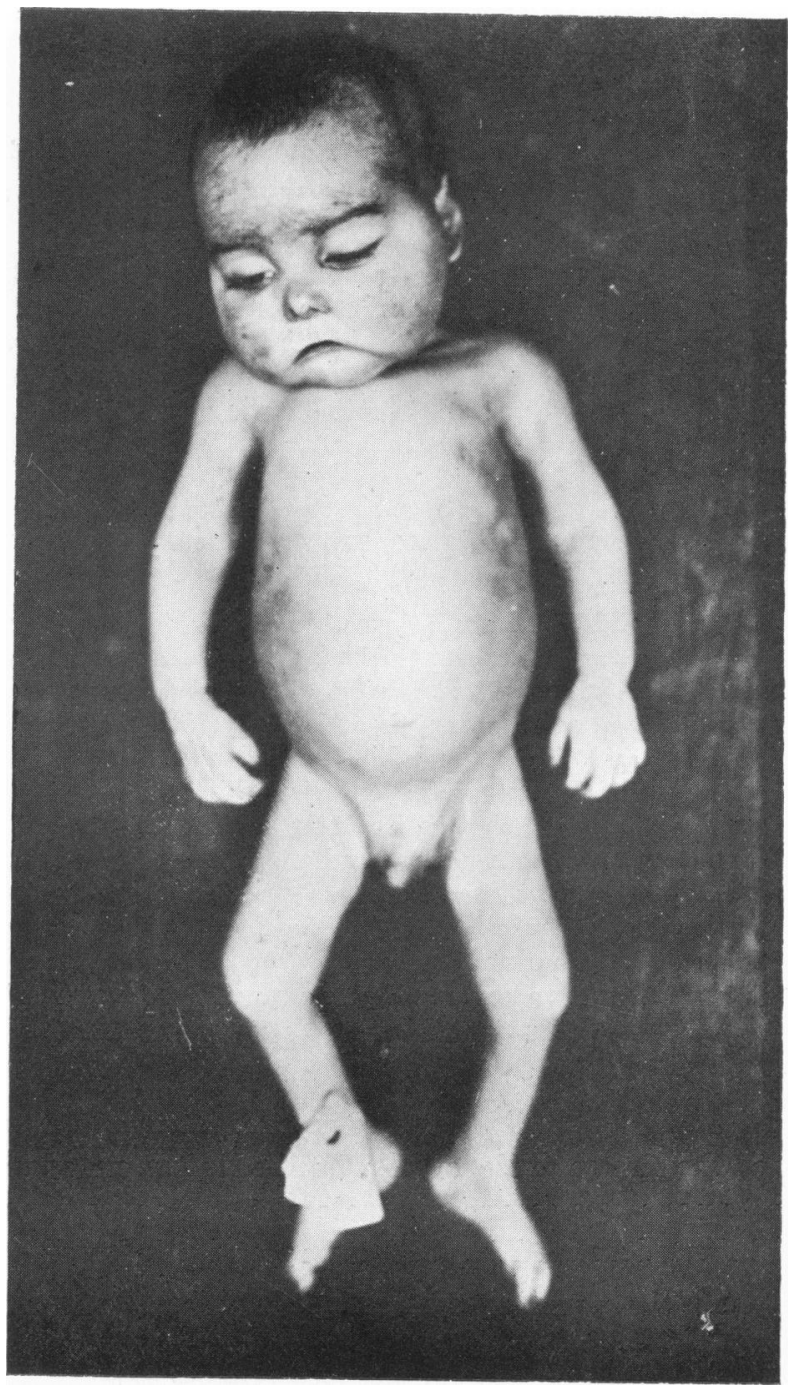

FIG. 1. - Post-mortem photograph. Note the fat, blotchy cheeks and hairiness of the forehead.

The appearance of the baby (Fig. 1) was very peculiar on account of the visible, hard deposits of fat in the cheeks and around the shoulders and scapulæ. The cheeks had a florid colour bringing to mind the countenance of a bar attendant accustomed to good living. The hair on the head was plentiful, and there was a slight abnormal hairiness of the forehead, but no development of hair elsewhere. The skin was dry and scaly in places, the legs wasted, and genitalia normal. There was no enlargement of lymphatic nodes. In the left flank was a mass which felt larger and lower than a 
normal left kidney. The right kidney was palpable and the liver not enlarged. The urine was normal and the Wassermann reaction negative. A tentative diagnosis of left (cortical) suprarenal tumour was made; horseshoe kidney and congenital cystic kidney also being considered in the diagnosis.

After admission the infant's weight fell steadily. In a week the temperature and respiration rate began to rise and signs of pneumonia appeared in the right lung.

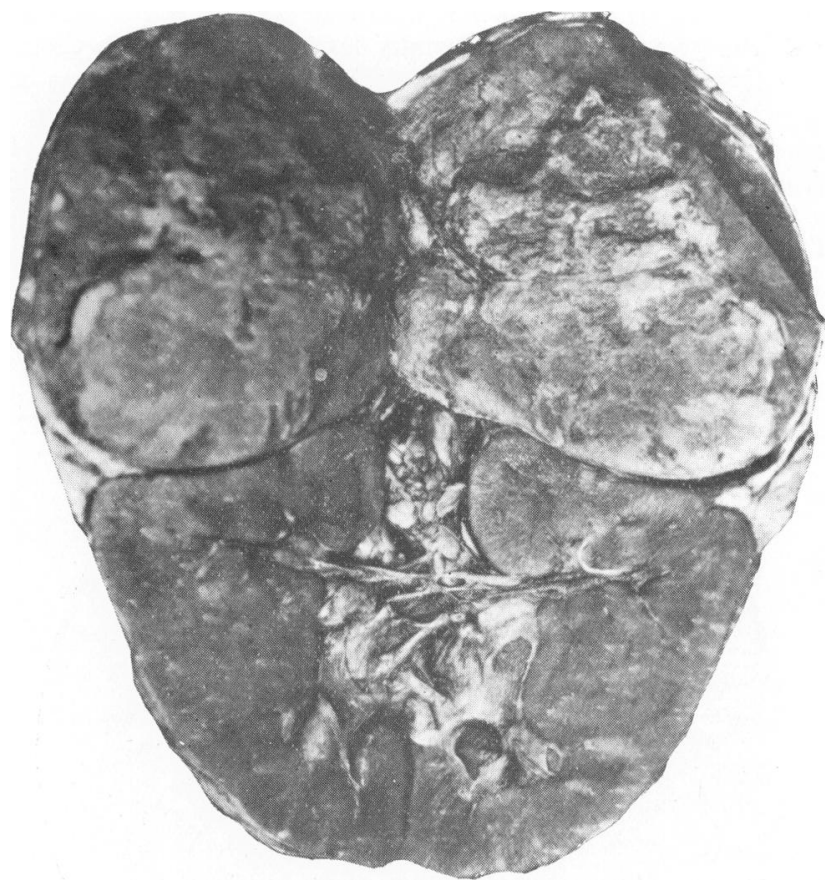

Fig. 2. -Adenoma of the suprarenal cortex. The upper pole of the kidney is flattened out by the tumour.

At this time a routine blood count presented the interesting feature of nearly 4,000 normoblasts per c.mm. (28 per 100 white cells counted) :-

\begin{tabular}{|c|c|c|c|c|c|c|c|}
\hline Red blood cells & $\ldots$ & $\ldots$ & $\ldots$ & $\ldots$ & $4,375,000$ & per & c.mm. \\
\hline Hæmoglobin & $\ldots$ & $\ldots$ & $\ldots$ & $\ldots$ & 60 & per & cent. \\
\hline Colour index & $\ldots$ & $\ldots$ & $\ldots$ & $\ldots$ & .7 & & \\
\hline White blood cells & $\ldots$ & $\ldots$ & $\ldots$ & $\ldots$ & 14,000 & per & c.mm. \\
\hline Polymorphonu & dclears & $\ldots$ & $\ldots$ & $\ldots$ & 20 & per & cent. \\
\hline Lymphocytes & $\ldots$ & $\ldots$ & $\ldots$ & $\ldots$ & 73 & , & , \\
\hline Monocytes & $\ldots$ & $\ldots$ & $\ldots$ & $\ldots$ & 5 & , & , \\
\hline Myelocytes & $\ldots$ & $\ldots$ & $\ldots$ & $\ldots$ & 1 & , & , \\
\hline Lymphoblasts & $\ldots$ & $\ldots$ & $\ldots$ & $\ldots$ & 1 & ,, & ,", \\
\hline
\end{tabular}

Poikilocytosis, anisocytosis and polychromasia were noted.

The temperature rose to $103^{\circ}$, diarrhoea and vomiting began, and eleven days after admission the patient died.

Autopsy. There was an excess of fat over the thorax, neck and upper part of the back. The legs and arms were wasted in contrast to the plump face and thorax. The fat was firm and had the appearance of beef suet. The sucking pads were large. There was pneumonic consolidation of the right lung. The left ventricle was hypertrophied, its wall being 8 to $10 \mathrm{~mm}$. thick. The kidneys were of average size for this age. The left suprarenal formed a round mass as large as the left kidney to which it was attached (Fig. 2). The tumour was completely encapsuled; no infiltration could be seen, and no metastases. The tumour had displaced the left kidney downwards into the left loin, making it abnormally palpable during life. On sectiou 
the suprarenal tumour presented macroscopically a heterogeneous appearance in which areas of hæmorrhage and necrosis could be recognized.

On microscopical examination the main part of the section, stained with hæmatoxylin and eosin, was seen to consist of a mass of cortical cells which formed a cortical adenoma (Fig. 3). In this adenoma there was no trace of the normal arrangement in zones. The cells were arranged, however, in a manner closely similar to the normal : cell-groups and trabeculæ being separated by capillaries and delicate collagen fibrils. Some of the groups were abnormally large, and the cells themselves, though they varied in size, were typical of cortical cells and there was no evidence of malignancy (Fig. 4). On the surface of the tumour was a portion of suprarenal showing a more normal arrangement, except that here was seen a fibrosis of the medulla which contained no glandular tissue, and the cortex, fibrosed in some places, was elsewhere hyperplastic.

Dr. H. M. Turnbull, who kindly examined the tumour, described it as a cortical adenoma (or benign hypernephroma), and Dr. H. A. Lucas, who also kindly gave an opinion, agreed that there were no signs of malignancy.

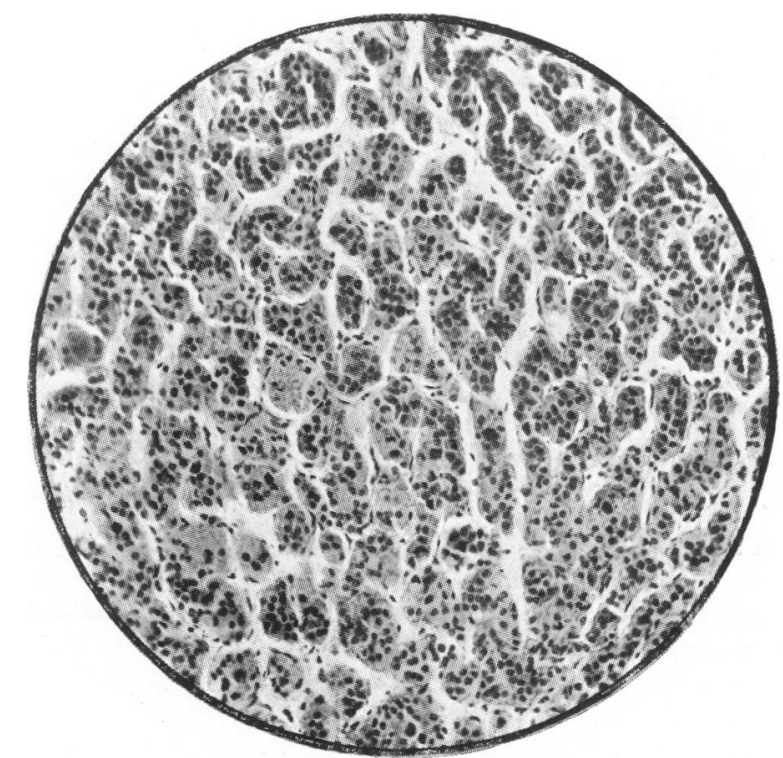

Fic. 3.-Microphotograph of cortical adenoma showing the arrangement of the cells in groups and columns. (Low power $\times 100)$.

Ewing ${ }^{13}$, in 'Neoplastic Diseases,' points out that the distinction between adenoma and nodular hyperplasia of the adrenal cortex is not a sharp one and that, indeed, it is possible for the two processes to be found side by side in the same gland (Letulle). Malignant transformation in such tumours is of relatively common occurrence.

\section{Discussion.}

This case combined slight hypertrichosis with obvious adiposity. Pathologically the neoplasm was unilateral and apparently benign in character, although it is possible that, had the infant survived longer, secondary deposits might have been formed. To fix the date at which the tumour process became active we can be guided by the appearance of macrosomia at eleven weeks, suggesting that the disease was entirely postnatal. It is reasonable to leave it an open question whether a longer course 
would have given time for the features of malignancy to manifest themselves, and it should be remembered in this connection that malignant cortical hypernephromata may be expected to metastasize slowly.

The histological appearances in this case were very similar to those seen in the micro-photographs reproduced in Bulloch and Sequeira's paper, and, except for the absence of secondary deposits, the pathological findings must have been very similar. Moreover, the same macroscopical and microscopical similarities crop up again and again in the literature of these tumours.

High blood pressure with cortical tumours has been recorded ${ }^{14},{ }^{15}$, and the finding of hypertrophy of the left ventricle in the present case, without any cardiovascular or rena! explanation, was of great interest. Unfortunately no record of the blood pressure had been secured. In cases of cortical

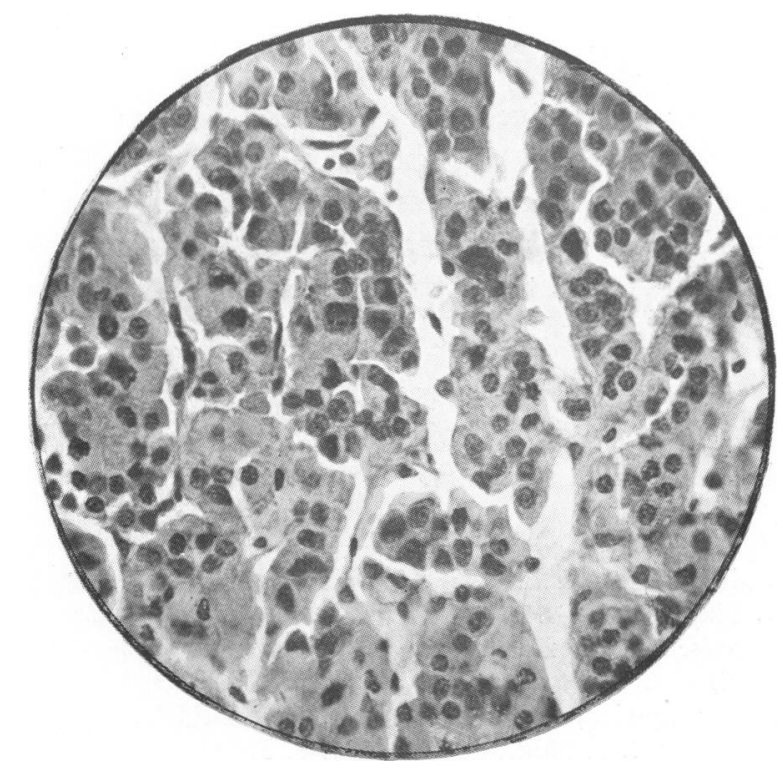

Fit. 4.-Microphotograph of cortical ade:soma. The cortical cells vary in size and shape and they ars separated by capillary loops. (High power $\times 250)$.

tumour with raised blood pressure, an associated functional hyper-activity of the suprarenal medulla has been suggested, and whatever its explanation may be its occasional occurrence must be accepted. Increased vascular supply of the tumour-bearing gland, with increased activity of the medulla, might be put forward in explanation, except that raised blood pressure is the exception rather than the rule in nearly all types of suprarenal tumours, even in the medullary ones themselves. Indeed, it is only in that rare variety, the suprarenal paragangliomata, that high blood pressure is a feature. On the other hand, it may be that cells of the cortex themselves elaborate a pressor hormone and this explanation would fit the facts more satisfactorily.

Recently, our knowledge of the action of a cortical hormone has been increased by the experiments of Hartman, MacArthur, Brownell and Hartman $^{16}$ and by those of Swingle and Pfiffner ${ }^{18}$. These two groups of 
workers have independently prepared extracts of the adrenal cortex which they have shown to be capable of prolonging indefinitely the lives of adrenalectomized animals. Both the Swingle-Pfiffner extract and the Hartman extract (Cortin) ${ }^{17}$ have been tried in the treatment of Addison's disease with striking benefit. Details of seven cases treated with the extract of Swingle and Pfiffner have been recorded ${ }^{19}$, though blood pressure readings taken after the treatment are mentioned in but two of them. In the first, the blood pressure before treatment was $80-84 \mathrm{~mm}$. systolic, and 58-60 $\mathrm{mm}$. diastolic. After treatment it was 106 systolic, and 58 diastolic. In the second, the initial reading was 82 systolic and 64 diastolic, and after treatment it was 100 systolic and 75 diastolic. The earlier cases in this series received an extract not quite free from adrenalin, so that observations on them would not have been helpful for our purpose. The Hartman extract revived a patient with a systolic pressure of $50 \mathrm{~mm}$. The Swingle and Pfiffner extract proved effective, as a rule, within 48 to 72 hours. The most striking results were a return of appetite, a sense of well-being and a gain in weight. The rise in blood pressure did not appear to be striking in comparison with the subjective improvement, though perhaps it would be wrong for us to assume that the cortical extracts so far employed have been capable of exerting a full physiological action.

My thanks are due to Dr. Robert Hutchison for permission to publish the details of this case, and to Professor H. M. Turnbull and to Dr. H. A. Lucas for their histological opinions.

\section{REFERENCES}

1. Meckel, F., Abhandlungen aus der Menschlichen und Vergleichenden Anat. und Physiol., Halle, 1806, 164. (Quoted by W. Bulloch and J. H. Sequeira.)

2. Otto, Pathologisch-Anat. Beobachtungen, 1816, 139. (Quoted by Apert, Bull. med., 1910.)

3. Bulloch, W., \& Sequeira, J. H., Tr. Path. Soc. Lond., London, 1905, LVI, 189.

4. Hutchison, R., Quart. J. Med., Oxford, 1907-8, I, 33.

5. Frew, R. S., Ibid, 1911, IV, 123.

6. Glynn, E., Ibid, 1912, V, 157.

7. Holmes, G., Ibid, 1925, XVIII, 143.

8. Hutchison, R., Brit. J., Child. Dis., London, 1904, I, 258.

9. Guthrie, L., \& Emery, W. d'E., Clin. Soc. Trans., London, 1907, XL, 175.

10. Adams, C. E., Tr. Path. Soc. Lond., London, 1905, LVI, 208.

11. Collett, A., Norsk. Mag. f. Laegev., Christiania, 1923, XXXIV, 609; and Am. J. Dis. Child., Chicago, 1924, XXVII, 204.

12. Hutchison, R., \& Lightwood, R., Arch. Dis. Childh., Lond., 1931, VI, 257.

13. Ewing, J., Neoplastic Diseases, Philad., 1928, 3rd Ed., 811.

14. Weber, F. Parkes, Practitioner, Lond., 1920, CV, 181.

15. Winkel, M., Deut. Arch. f. klin. Med., Leipzig, 1928, CLIX, 1. (Quoted by F. Parkes Weber.)

16. Hartman, F. A., MacArthur, C. G., \& Hartman, W. E., Proc. Soc. Exper. Biol. and Med., N.Y., 1927, XXV, 69.

17. Hartman, F. A., Brownell, K. A., \& Hartman, W. E., Am. J. Physiol., Baltimore, 1930, XCV, 670 .

18. Swingle, W. W., \& Pfiffner, J. J., Science, N.Y., 1930, LXXI, 321.

19. Rowntree, L. G., Greene, C. H., Swingle, W. W., \& Pfiffner, J. J., J. Am. Med. Ass., Chicago, 1931, XLVI, 231.

20. Fordyce, A. D., \& Evans, W. H., Quart. J. Med., Oxford, 1929, XXII, 557. 